\title{
Multimodal hand hygiene program: twelve years of continuous improvement in the hospital
}

\author{
JY Kawagoe ${ }^{1,2^{*}}$, AR Toniolo ${ }^{1}$, CM Santos $^{1}$, CV Silva ${ }^{1}$, FG Menezes ${ }^{1}$, HF Castagna ${ }^{1}$, MF Cardoso ${ }^{1}$, P Gonçalves ${ }^{1}$, \\ LG Pontes ${ }^{1}$, L Correa $^{1}$
}

From 3rd International Conference on Prevention and Infection Control (ICPIC 2015)

Geneva, Switzerland. 16-19 June 2015

\section{Introduction}

Many organizations and infection prevention experts agree that effective hand hygiene $(\mathrm{HH})$ reduces the incidence of healthcare-associated infections (HAI). Multimodal strategies have been recommended to achieve successful and sustained $\mathrm{HH}$ improvement.[1]

\section{Objectives}

Present a twelve-year HH Multimodal Improvement Program at a private and large hospital.

\section{Methods}

Descriptive study about $\mathrm{HH}$ compliance improvement and HAI reduction at 650-bed hospital, in São Paulo, Brazil, by implementing multiple actions:

-selecting and installing a good alcohol-based hand rub (ABHR) at point of care with a training program called "Reminder project" (2003-2005);

- providing ongoing training and education and annual campaigns aiming at behavioral change focusing on ABHR as primary product and sustained compliance for $\mathrm{HH}$, using different strategies (formal and web-based training; campaigns with varied themes as "Hospital Safe Attitude", "Make a Commitment");

- evaluating and providing feedback on infrastructure and $\mathrm{HH}$ compliance, knowledge and perception;

- participating in National and State HH programs (2008 and 2011);

- applying Positive Deviance strategy as a motivational tool for $\mathrm{HH}$ promotion;

- achieving leadership and front-line staff commitment and patient and physician engagement.

\section{Results}

ABHR consumption (L/1000 patient-days) increased from 19.0 (2005) to 82.7 (2014) and $\mathrm{HH}$ compliance increased from $53.2 \%$ (2008) to $72.6 \%$ (2014). HAI incidence density rates per 1000 patient-days decreased from 16.2 (2003) to 4.2 (2014) and central line-associated bloodstream infections density rates reduction from 5.7 (2003) to 1.0 (2014).

\section{Conclusion}

Multimodal $\mathrm{HH}$ strategies and leadership engagement were essential to achieve these results. Sustain and improve $\mathrm{HH}$ compliance is a continuous challenge.

\section{Disclosure of interest}

None declared.

\section{Authors' details}

${ }^{1}$ Infection Control Service, Hospital Israelita Albert Einstein, São Paulo, Brazil. ${ }^{2}$ Nursing Post-graduation Course, Albert Einstein Nursing Faculty, São Paulo, Brazil.

Published: 16 June 2015

\section{Reference}

1. World Health Organization: WHO Guidelines on Hand Hygiene in Health Care: a Summary. Geneva: WHO; 2009.

\section{doi:10.1186/2047-2994-4-S1-O21}

Cite this article as: Kawagoe et al:: Multimodal hand hygiene program: twelve years of continuous improvement in the hospital. Antimicrobial Resistance and Infection Control 2015 4(Suppl 1):021.

${ }^{1}$ Infection Control Service, Hospital Israelita Albert Einstein, São Paulo, Brazil Full list of author information is available at the end of the article 